\title{
Study of chromium uptake by three yeasts: Saccharomyces cerevisiae, Candida tropicalis, and Yarrowia lipolytica
}

\author{
Laila Trioui $^{*}$, Darouiche Bouchra² ${ }^{2}$ Errachidi Faouzi², and Blaghen Mohammed ${ }^{1}$
}

1 Laboratory of Microbiology, Pharmacology, Biotechnology and Environment, Faculty of Sciences Ain Chock, University Hassan II of Casablanca, Morocco.

2 Nutrition unit, Agro-alimental and Environment Laboratory of human pathology Biomedical and environment, Faculty of Medicine and Pharmacy, University Sidi Mohamed Ben Abdallah, Fes, Morocco.

*Corresponding Author: Trioui Laila, Faculty of Sciences Ain Chock, University Hassan II of Casablanca B.P 5366 Maarif box. 20100 Casablanca Morocco;

Email: laila.trioui@gmail.com

TEL:00212661469664

Received date: 12 January 2018, Accepted date: 28 February 2019, Online date: 20 March 2019

Copyright: (c) 2019 Laila Trioui et al., This is an open-access article distributed under the terms of the Creative Commons Attribution License, which permits unrestricted use, distribution, and reproduction in any medium, provided the original author and source are credited.

\begin{abstract}
Heavy metal pollution is a topic that attracts a lot of environmental organization's attention. Recognizing the capacity of microorganisms and biological materials to remove heavy metals from contaminated sites, and their advantage to be a cheaper method of heavy metal remediation, many researches have been dedicated to study and optimize this kind of process. The present work is an eco-physiologic study of hexavalent chromium uptake phenomena, by three species of yeast, in order to investigate some transformations that occur on yeast cell during exposure to chromium. The aim of this work is to optimize the chromium uptake by yeasts, by enlarging the knowledge about the fixation mechanism, in order to use this natural process for reducing the hexavalent chromium pollution from effluent contaminated by this dangerous heavy metal. The yeast growth was performed by kinetic evolution in liquid culture, the sucrose dosage was obtained by DNS protocol, the enzymatic dosage was done by Sinha colometric technique for catalase dosage, and by Nelson methodology for invertase dosage, the amount of chromium was determined by using atomic absorption spectrophotometry (AAS). Results demonstrate that chromium impact yeast growth in the cultivation medium even in low chromium concentration, a better resistance of Saccharomyces cerevisiae was observed, also this stain shows better performance in chromium bioaccumulation. The decrease of catalase in the yeast cells while exposure to chromium confirms the intra-cellular impact. As invertase exists in the soluble spaces of the cell membrane and in the vacuoles, its release during exposure to chromium suppose his complexation with chromium which enforce his passage through the membrane. Efficiency of chromium uptake by Saccharomyces cerevisiae attained $90 \%$ with a concentration of $0,5 \mathrm{~g} / \mathrm{l}$ of chromium. The promising yield given by Saccharomyces cerevisiae can be used in a natural chromium decontamination process. As perspective, this work can be used for further studies about the invertase-chromium complexation to profit from this capacity to extract invertase from yeast, for industrial use. The results obtained through this study indicate the possibility of treating a contaminated waste effluent with chromium, by using Saccharomyces cerevisiae.
\end{abstract}

Keywords: Candida spp, medicinal plant, Citrullus colocynthis extract, Vaginal Candida Infections, bioactive compounds, antifungal resistance

\section{INTRODUCTION}

A lot of researches was investigated to understand better heavy metals toxicity, the public awareness of environmental pollution were the driving forces for enactment and enforcement of stricter legislation on the discharge of the toxic heavy metal contaminants [1]. Many aquatic environments have received heavy metals with concentrations exceeding water quality standards, that are designed to protect the environment. Consequently, the development of cost-effective management systems and treatment technologies becomes paramount. The industries activating in metal finishing, electroplating, leather tanning, stainless steel production, and textile, produce large flows of contaminated water containing high concentrations of chromium [2]. Natural occurring of chromium in water, arise from mineral weathering processes, soluble organic chromium, sediment load, and precipitations [3]. Frequently, chromium is released by environmental accidents from anthropogenic sources as well as natural geochemical processes [4,5]. 
Chromium contamination problems are often exacerbated because it can be dispersed to a human being, through the food chain, and cause serious hazards [6]. Chromium is one such heavy metal that has recently received widespread attention because of its interesting proprieties used in various industrial applications [7]. It is well known that chromium exists mainly as two stable oxidation states, hexavalent chromium $\mathrm{Cr}$ (VI) and trivalent chromium $\mathrm{Cr}$ (III) [8]. $\mathrm{Cr}$ (III) compounds are less toxic, mobile and available for biological uptake [9], while $\mathrm{Cr}(\mathrm{VI})$ compounds are more toxic than $\mathrm{Cr}(\mathrm{III})$ compounds due to their high solubility in water, their rapid permeability through biological membranes and subsequent interaction with intracellular proteins and nucleic acids $[10,11]$.

Recently, the commonly used methods applied to remove excessive hexavalent chromium from aqueous solutions are: ion exchange, chemical precipitation, activated carbon adsorption, evaporation and membrane processes, all those methods are inappropriate for reaching levels of decontamination required by the regulations, they are expensive, and are in most of the cases associated with the generation of secondary environmental problems by creating waste disposal [12].

Early in the adoption of bioremediation within the commercial marketplace, it became clear that indigenous microflora could be a powerful tool in the clean-up of readily biodegradable contaminants [13], the limitations of such methods were also recognized, and many were giving attention to improving additional research to make bioremediation more viable commercially. Several reports were published, analyzing bioremediation research needs, and several of the recommendations of these reports can also be seen as potential strategies for the improvement of bioremedial microorganisms through genetic engineering or other methods. Many of these assessments were the need for integrated multidisciplinary approaches (e.g., microbiology, engineering, etc.) to understand how bioremediation works in the field and how these processes can be optimized for industrial use [14]. Also, these reports often called for expanded field research and better abilities to model and monitor field remediation Many microorganisms were recognized by their ability to heavy metals remediation, [15,16], in comparison with bacteria and fungi, yeast has proved a big competence and adaptation to different parameters like $\mathrm{pH}$, temperature, the occurrence of nutrients and high contaminant concentration [17,18]. Therefore, in the present paper we studied, the response of three representative yeast strain (Saccharomyces cerevisiae, Candida tropicalis, and Yarrowia lipolytica), to chromium exposure with a focus on sugar consumption and on the changes, that occur on invertase and catalase enzymes, to understand chromium toxicity.

\section{MATERIALS AND METHODS}

\section{Chemicals and biomaterials:}

The yeasts used were selected within 72 stains, Saccharomyces cerevisiae 122 (SC) was collected from tannery effluent, Candida tropicalis EF14 (CT), and Yarrowia lipolytica 67 (YL) were isolated from olive mill wastewater, the characterization and identification were done by the Kreger-van Rij taxonomic key [19].

The yeasts were conserved in $-40^{\circ} \mathrm{C}$, in a culture medium of yeast peptone glucose (YPG) with glycerol (50\%). When the conservation exceeds 3 mounts, we use inclined agar test tube.

The toxicity tests are done in the same medium (YPG) in petri dishes.

Standard solution of hexavalent chromium $(1000 \mathrm{mg} / \mathrm{L})$ was prepared by dissolving the required amounts of analytical grade potassium dichromate $\left(\mathrm{K}_{2} \mathrm{Cr}_{2} \mathrm{O}_{7}\right)$ in distilled water, different concentrations of the solution were then prepared by progressive dilution of the stock solution.

\section{Growth monitoring:}

The yeast growth monitoring (kinetic evolution), was performed in a $250 \mathrm{ml}$ Erlenmeyer, containing $100 \mathrm{ml}$ liquid culture medium with a chromium concentration of $0,1 \mathrm{~g} / 1$ (the adequate concentration, based on the inhibitory test below), prepared by dissolving the standard solution of chromium. The culture medium used is YPS (Y: yeast 1\%, P: peptone 2\%, and S: sucrose 2\%). The initial $\mathrm{pH}$ value of the medium was adjusted to 5.5 with $1.0 \mathrm{M} \mathrm{NaOH}$ and $0.1 \mathrm{M} \mathrm{HCl}$ and then inoculated with an inoculum of $100 \mu 1$ ( 200 cells). Cultures were aerated in an adapted bioreactor with $150 \mathrm{rpm}$ and $25^{\circ} \mathrm{C}$. At timed intervals, cells were harvested by centrifugation and analyzed.

The monitoring of the growth is done by calculating the optical density in $620 \mathrm{~nm}$.

\section{Sucrose dosage:}

Sucrose was used in the medium as a carbon source, to study the sucrose consumption, we proceed to the dosage of the glucose obtained by inversion of sucrose by DNS protocol [20]. DNS protocol is based on titration of reducing sugars by dinitrosalicylic acid (DNS).

A standard range of concentration of sucrose in the medium from 0 to $1 \mathrm{~g} / \mathrm{l}$ was used. The result was read by spectrophotometry in the 540nm wavelength. The optical density difference between sample and check sample gives the amount of reducing sugars liberated. One international unit of invertase corresponds to $1 \mu$ mole of reducing sugars liberated in 3 minutes for $1 \mathrm{mg}$ dried matter used.

\section{Determination of the chromium minimum inhibitory concentration:}

The minimum inhibitory concentration was performed using YPG agar medium, with different chromium concentration $(0$ to $1 \mathrm{~g} / \mathrm{l})$, prepared by dissolving the standard solution of chromium $\left(\mathrm{K}_{2} \mathrm{Cr}_{2} \mathrm{O}_{7}\right)$. The yeast was pre-cultured in a liquid solution for 
18h, an inoculum of $100 \mu 1$ (200 cells) was spread on a petri dish of YPG with chromium, as a standard we used a medium without chromium.

The growth was estimated, by the colony number on the medium.

The mortality rate was calculated by the bellowing equation:

$$
T=\left(1-\left(\frac{N}{N_{0}}\right)\right) \times 100
$$

N0: Colony number on the medium without chromium.

$\mathrm{N}$ : Colony number on the medium with chromium.

We achieve exhaustion, by spreading, to test the consistency of the test.

\section{Enzymatic dosage: \\ Catalase dosage:}

The test of catalase was performed to check the intracellular toxicity of chromium. We used the colorimetric technique of Sinha [21]. The dichromate is reduced by acetic acid to chromic acetate when heated in the presence of $\mathrm{H}_{2} \mathrm{O}_{2}$, with the formation of perchromic acid as an unstable intermediate, then chromic acetate produced is measured calorimetrically since dichromate has no absorbency in this region. The reagent was prepared with $5 \%$ of $\mathrm{K}_{2} \mathrm{Cr}_{2} \mathrm{O}_{7}$ and $1 / 3$ volume proportion of acetic acid. The dosage was done by adding $100 \mu \mathrm{l}$ of yeast extract (grinded and prepared in phosphoric buffer), and $300 \mu \mathrm{lof} \mathrm{H}_{2} \mathrm{O}_{2}(2 \mathrm{mM})$ and buffer solution of phosphate $(\mathrm{pH}=7,4)$ : After $5 \mathrm{~min}$, we add $2 \mathrm{ml}$ of the reagent dichromate/acetic acid to stop the reaction, the remaining $\mathrm{H}_{2} \mathrm{O}_{2}$ is determined by measuring chromic acetate by spectrophotometry after $10 \mathrm{mi} \mathrm{n}$, in $570 \mathrm{~nm}$ wavelength. A standard curve with $\mathrm{H}_{2} \mathrm{O}_{2}$ was used to calculate catalase activity, the activity of catalase is expressed in $\mu$ moles of the consumed $\mathrm{H}_{2} \mathrm{O}_{2} / \mathrm{min} / \mathrm{g}$ protein, which is the specific activity (SA).

\section{Invertase dosage:}

Invertase activity was assayed by measuring the amount of reducing sugars released from sucrose, by Nelson methodology [22]. The assay mixture for invertase contained enzyme extract $(0.1 \mathrm{ml})$ and sucrose $[0.9 \mathrm{ml}$ of $1.1 \%(\mathrm{w} / \mathrm{v})]$ in $100 \mathrm{mM}$ sodium acetate buffer ( $\mathrm{pH} 5.5)$. The mixture was incubated at $60^{\circ} \mathrm{C}$ for $1 \mathrm{~h}$, and then reaction was stopped by adding $1 \mathrm{ml}$ of Nelson's reagent, after cooling. The optical density at $540 \mathrm{~nm}$ of each sample is read in comparison with its control. One unit of invertase (U) was defined as that amount of sugar, which was determined about a standard curve and the specific enzymatic activity (SA) is expressed by $\mu \mathrm{mol} / \mathrm{min} / \mathrm{ml}$. The calibration curve was drawn with fructose $(10-100 \mathrm{mg})$.

\section{Chromium dosage:}

The Chromium dosage in the liquid culture medium was performed in a $250 \mathrm{ml}$ Erlenmeyer, containing $100 \mathrm{ml}$ liquid culture medium with a chromium concentration of $0,1 \mathrm{~g} / 1$, the culture medium used is YPS.

The initial $\mathrm{pH}$ value of the medium was adjusted to 5.5 with $1.0 \mathrm{M} \mathrm{NaOH}$ and $0.1 \mathrm{M} \mathrm{HCl}$ and then inoculated with an inoculum of $100 \mu 1$ ( 200 cells). Cultures were aerated in an adapted bioreactor with $150 \mathrm{rpm}$ and $25^{\circ} \mathrm{C}$. At timed intervals, the supernatants were collected and separated by centrifugation. The remaining chromium is determined using atomic absorption spectrophotometer (AAS) type Shimadzu 7000 AA with deuterium background corrector. All measurements were carried out in an air/acetylene flame.

\section{Chromium toxicity static studies on solid medium:}

This preliminary chromium toxicity study on YPG medium was performed by the monitoring of the yeast growth according to chromium concentration, we proceed by detecting the critical concentration (just before the Minimal Inhibitory Concentration) to define the physiologic background of our study. 


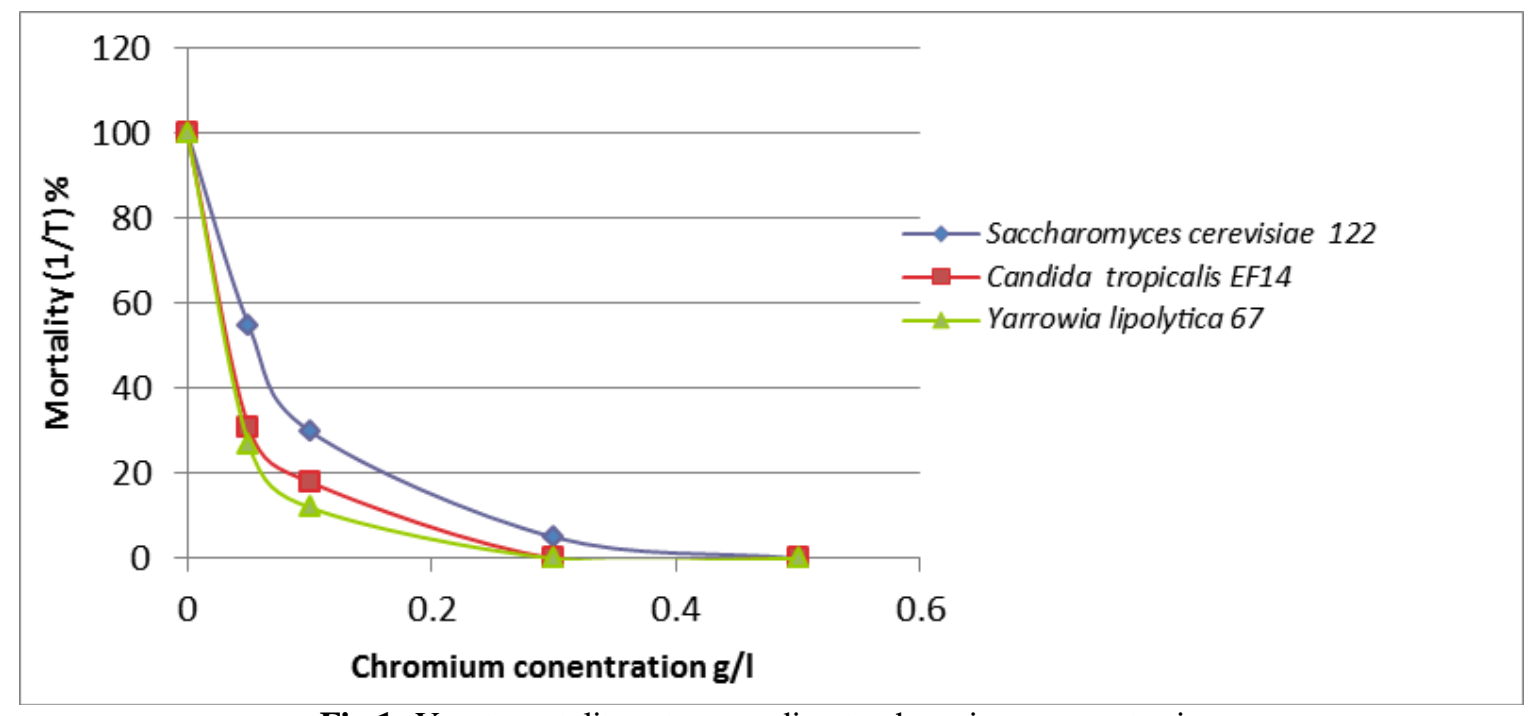

Fig.1: Yeast mortality rate according to chromium concentration

The curve (Fig.1) demonstrates the chromium toxicity from the smaller dose; it's a logarithmic model which correlate with toxicities models [23]. The concentration $0,5 \mathrm{~g} / 1$ matches with the maximum mortality rate (total death) for the three yeasts, we note that Saccharomyces cerevisiae 122 is less influenced than Candida tropicalis EF14 and Yarrowia lipolytica 67. The figure demonstrates that the concentrations, $0.1 \mathrm{~g} / 1$ is favorable for the chromium toxicity study, there is not excessive mortality, like in high concentration (from $0.3 \mathrm{~g} / \mathrm{l}$ to $0.5 \mathrm{~g} / \mathrm{l}$ ). $\mathrm{SC}$ showed a better resistance in the presence of chromium than the other stains.

\section{Study of the chromium toxicity kinetic on liquid medium:}

Study of biomass growth:

After identification of critical toxic concentration of chromium, the choice of the $0,1 \mathrm{~g} / \mathrm{l}$ concentration for next studies was effective to minimize the cells mortality, which happens in high chromium concentration. Also, it is the middle concentration that can give significant information about the tested yeast. The result of the kinetic studies is presented in Fig.2.

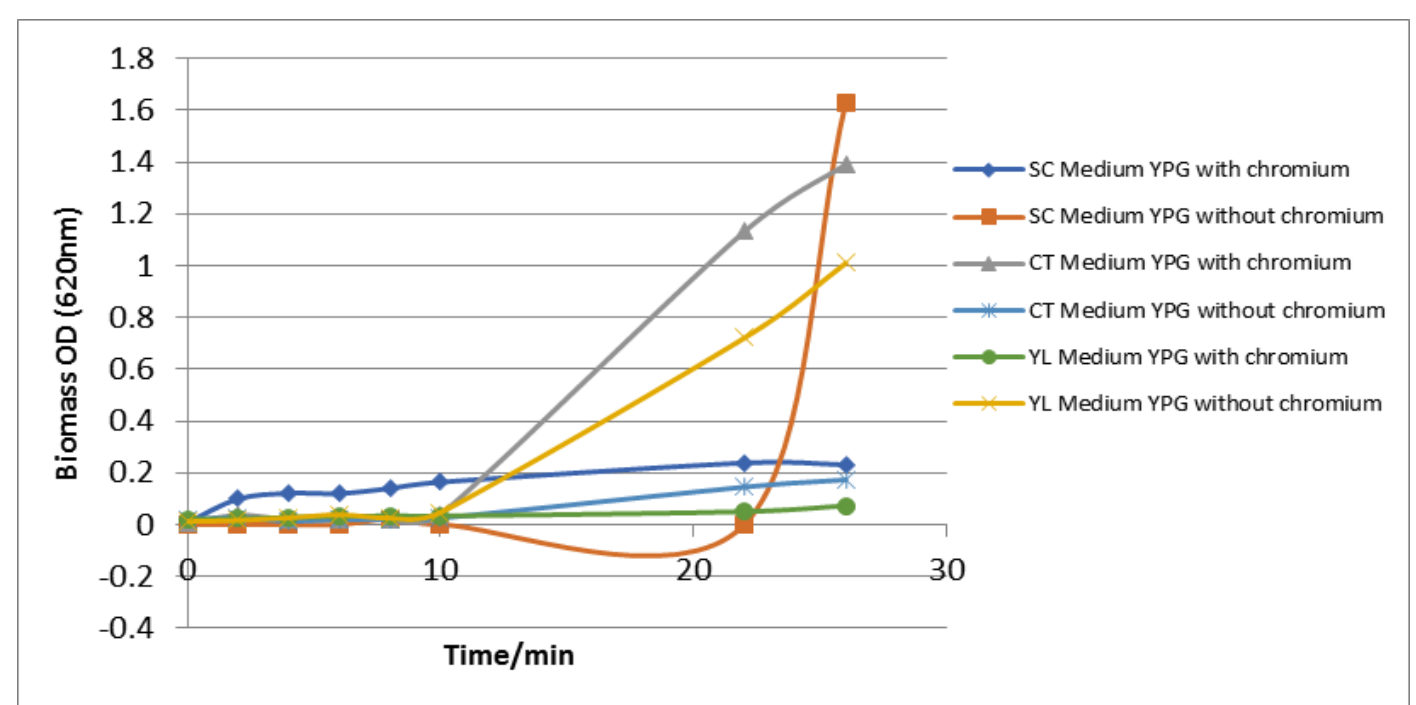

Fig.2: Tested stain growth kinetics evolution, with and without chromium

The figure shows that the studied yeast has different kinetic inthe presence of chromium; the growth rate is more effective without chromium. Chromium impact directly the yeast growth.

It showed a better resistance of SC.

\section{Substrate consumption study:}

Regarding obtained result, the rate of sugar consumption was influenced by chromium.

The substrate (glucose) consumption gives a good indication of yeast behavior, preceding studies shown that the cytoplasmic glycolic enzyme and mitochondrial enzyme are very influenced by chromium [24], that gives the yeast a tendency to make efforts to rebuild the damaged organs (cell maintenance), by enhancing the substrate consumption, it's the case for SC Fig.3. Other yeasts have less substrate consumption. 
This is an adaptation form which allows SC to resist more in hard stress situation induced by chromium comparing with other yeasts.

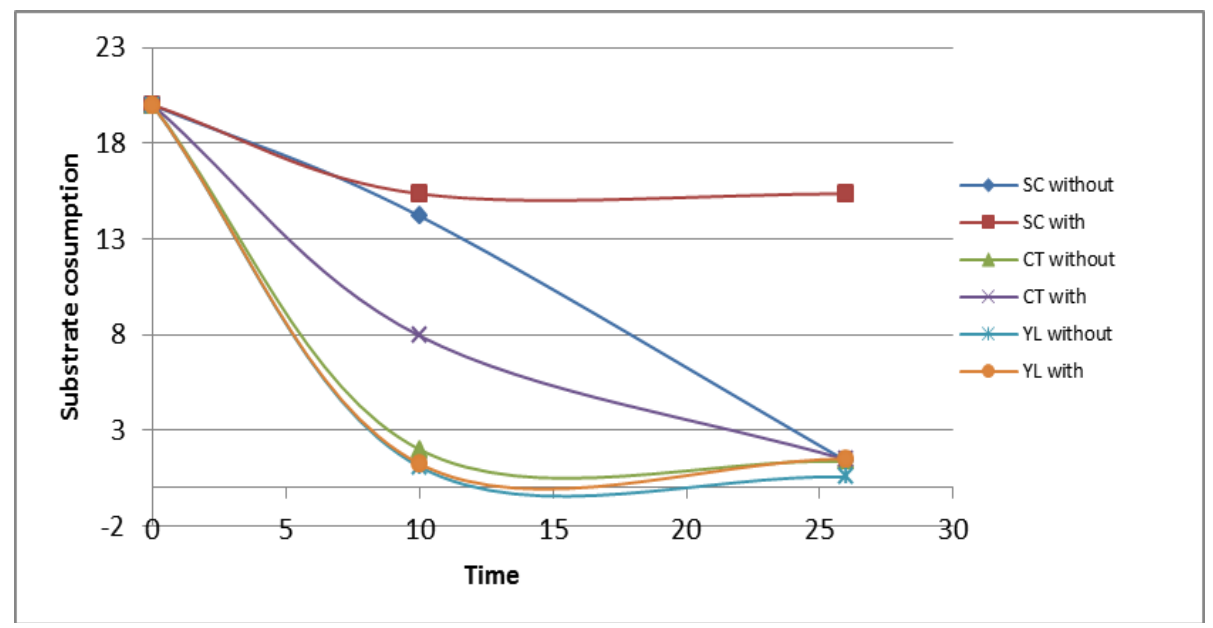

Fig. 3. Yeast substrate consumption kinetics with and without chromium.

Toxicity studies by catalase and invertase activity evaluation:

The study of the catalase enzyme was performed to control the tested yeast physiologic evolution. The results were resumed in Table 1.

Table.1. Catalase and Invertase activity expressed by specific activity $(\mathrm{SA} / \mathrm{ml})$.

\begin{tabular}{|l|l|l|l|l|l|l|}
\hline Stain / chromium & $\mathrm{SC}-\mathrm{Cr}$ & $\mathrm{SC}+\mathrm{Cr}$ & $\mathrm{CT}-\mathrm{Cr}$ & $\mathrm{CT}+\mathrm{Cr}$ & $\mathrm{YL}-\mathrm{Cr}$ & $\mathrm{YL}+\mathrm{Cr}$ \\
\hline SA catalase / $\mathrm{ml} /$ cell & 16,93 & 13,75 & 14,87 & 13,75 & 14,25 & 10,75 \\
\hline SA invertase / ml /cell & 165 & 230 & 216 & 235 & 256 & 280 \\
\hline
\end{tabular}

$\begin{array}{lc}\text { SC -Cr: Saccharomyces cerevisiae test without chromium. } & \text { SC +Cr: Saccharomyces cerevisiae test with chromium. } \\ \text { CT Cr: Candida tropicalis test without chromium. } & \text { CT }+ \text { Cr: Candida tropicalis test with chromium. } \\ \text { YL -Cr: Yarrowia lipolytica test without chromium. } & \text { YL+Cr: Yarrowia lipolytica test with chromium. }\end{array}$

SA: Specific Activity

Table 1. show that the specific catalase activity has a low rate in the presence of chromium, the invertase in contrary is more important in the presence of chromium.

The catalase takes place in the peroxisomes localized in the mitochondria [25], normally the catalase is released during the metabolism of sugar in the mitochondria (release of $\mathrm{H}_{2} \mathrm{O}_{2}$ ), [26], The low rate of catalase activity in the presence of chromium can be explained by the intracellular invasion of chromium.

The Invertase is localized enclosed to insoluble structures of the cell membrane and vacuoles [27], and although it cannot escape until these membranes are broken by mechanical or enzymatic action, or during metabolism process [28]. The increase of invertase activity in the presence of chromium can suppose that it was dragged by complexation with chromium during its passage through the cell membrane, chromium was used in many studies as a cross-linker [29], for invertase immobilization.

\section{Chromium dosage in liquid medium:}

As shown in the Fig.4 the concentration of chromium decrease gradually in the medium, due to the bioaccumulation of chromium by the three yeast, SC shows a better capacity of chromium fixation comparing with other yeast. 


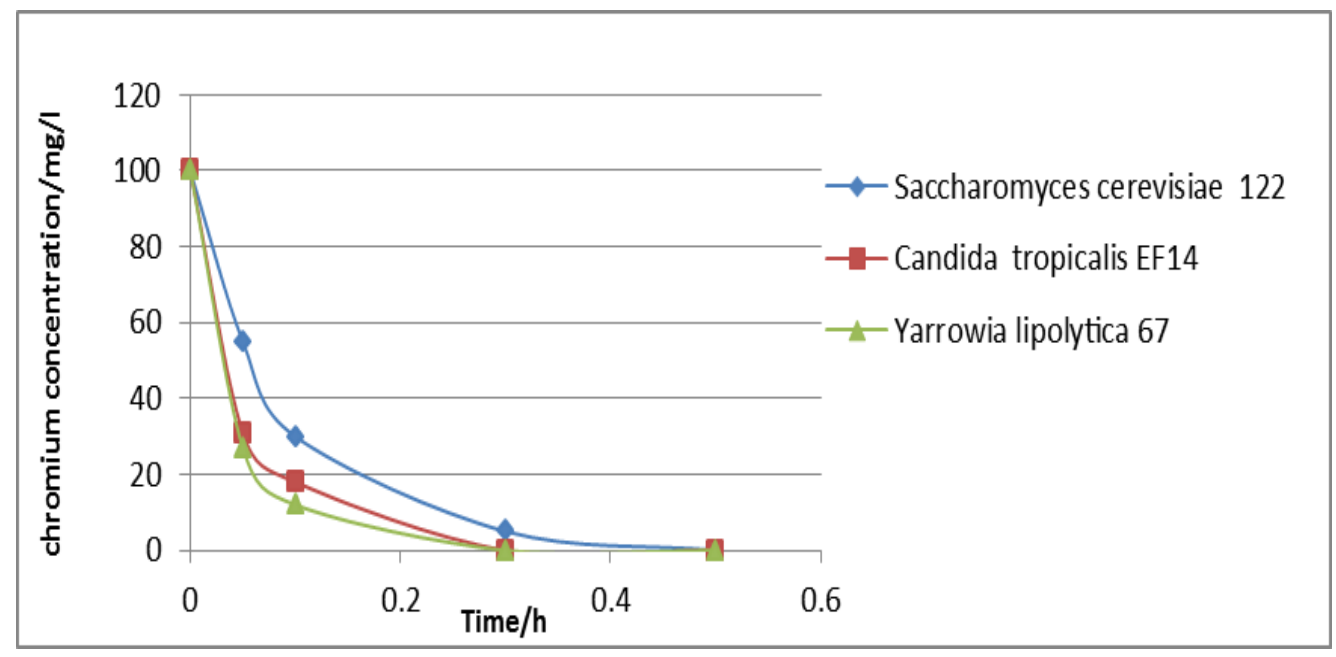

Fig.4. Chromium concentration evolution in the liquid medium.

\section{CONCLUSION}

The three-used yeast showed a good performance in chromium (VI) bioaccumulation, with a better rate for Saccharomyces cerevisiae, this stain showed a better resistance, and a better adaptation to the stress-induced by chromium, by an increase of cellular maintenance. The catalase and invertase activity were impacted by chromium for the three yeasts; this suggests that the catalase activity was impacted by chromium due to his intracellular passage. The increase of invertase after the contact with chromium suppose the breaking of the cell membrane by chromium during his passage, allowing the invertase release. The rapid adaptation and resistance of Saccharomyces cerevisiae, allowed it to fix up to $90 \%$ of chromium, this promises the possibility to use this stain for a natural chromium decontamination process wish known to be more effective and cheap method comparing with the chemical methods. This work can be used as a draft to invent a program that prevent a mixture between a chromium contaminated effluent from industries activating in metal finishing, electroplating, leather tanning, stainless steel production, and textile, with a yeast contaminated effluent from industries using yeasts for fermentation, like the breweries that produce the beer, the mixture of the two effluent can promise a free auto-decontamination. As a perspective study must be performed to confirm the mechanism of the invertase release during yeast exposure to chromium, which can be used to extract Invertase for industrial use in fructose production.

\section{ACKNOWLEDGMENT}

I acknowledge the continuous support and comments received from the Nutrition unit, Agro-alimental and Environment Laboratory of human pathology Biomedical and environment, Faculty of Medicine and Pharmacy, University Sidi Mohamed Ben Abdallah, Fes, Morocco.The study is supported by the Faculty of Sciences Ain Chock, Hassan II university of Casablanca Morocco.

Authors declare no conflict of interest

\section{CONFLICT OF INTEREST:}

\section{REFERENCES}

1. Govind P, Madhuri S. Heavy metals causing toxicity in animals and fishes. Int J Pharm Pharm Sci. 2014;Vol 6,.

2. Ahamed MIN, Chandrasekaran N, Mukherjee A. Innovare Academic Sciences. 2014; 4-6.

3. Izbicki JA, Wright MT, Seymour WA, Mccleskey RB, Fram MS, Belitz K, et al. Applied Geochemistry Cr ( VI ) occurrence and geochemistry in water from public-supply wells in California. Appl Geochemistry. Elsevier Ltd; 2015;63: $203-217$. doi:10.1016/j.apgeochem.2015.08.007

4. Potapowicz J, Szumi D, Polkowska Ż. Science of the Total Environment The in fl uence of global climate change on the environmental fate of anthropogenic pollution released from the permafrost Part I . Case study of Antarctica. 2018;651: 1534-1548. doi:10.1016/j.scitotenv.2018.09.168

5. Tchounwou PB, Yedjou CG, Patlolla AK, Sutton DJ. Heavy Metals Toxicity and the Environment. 2014; 1-30. doi:10.1007/978-3-7643-8340-4

6. Bougherira N, Hani A, Djabri L, Sedrati N, Haied N, Toumi F. Mobility of chromium and tin associated with geochemical dynamics in groundwater in Meboudja plain. Energy Procedia. Elsevier B.V.; 2014;50: 685-691. doi:10.1016/j.egypro.2014.06.084

7. Oliveira H. Chromium as an Environmental Pollutant: Insights on Induced Plant Toxicity. $2012 ; 2012$. doi: $10.1155 / 2012 / 375843$ 
8. Michalak I, Chojnacka K, Witek-krowiak A. State of the Art for the Biosorption Process - a Review. Appl Biochem Biotechnol. 2013;170: 1389-1416. doi:10.1007/s12010-013-0269-0

9. Smrithi, A; Usha K. Isolation and Characterization of Chromium Removing Bacteria From Tannery Effluent Disposal Site. Int J Adv Biotechnol Res. 2012;3: 644-652.

10. Wise SS, Pierce J, Sr W. NIH Public Access. 2014;733: 78-82. doi:10.1016/j.mrfmmm.2011.12.002.Chromium

11. Das M, Nigam H, Chauhan S, Pandey P, Swati P. Microbial chromium degradation: Biological evolution , mitigation and mechanism. 2015;6: 6-12.

12. Kan C, Ibe AH, Katrina K, Rivera P, Arazo RO, Daniel M, et al. Hexavalent chromium removal from aqueous solution by adsorbents synthesized from groundwater treatment residuals. Sustain Environ Res. Elsevier Ltd; 2017;27: 163-171. doi:10.1016/j.serj.2017.04.001

13. Ram Chandra, Bajgai RC, Georgieva N, Lazarova N. Bioremediation of chromium ions with filamentous yeast Trichosporon cutaneum R57. J Biol Earth Sci J Biol Earth Sci. 2012;201: $70-75 . \quad$ Available: http://www.journals.tmkarpinski.com/index.php/jbes\%5Cnhttp://jbes.strefa.pl

14. Dzionek A, Wojcieszy D, Guzik U. Natural carriers in bioremediation: A review. 2016;23: 28-36. doi:10.1016/j.ejbt.2016.07.003

15. Jin Y, Luan Y. applied sciences Effects and Mechanisms of Microbial Remediation of Heavy Metals in Soil: A Critical Review. 2018; doi:10.3390/app8081336

16. Ayangbenro AS, Babalola OO. A New Strategy for Heavy Metal Polluted Environments: A Review of Microbial Biosorbents. 2017; doi:10.3390/ijerph14010094

17. Alonso-del-real J, Lairón-peris M, Barrio E, Querol A. Effect of Temperature on the Prevalence of Saccharomyces Non cerevisiae Species against a S . cerevisiae Wine Strain in Wine Fermentation: Competition, Physiological Fitness , and Influence in Final Wine Composition. 2017;8. doi:10.3389/fmicb.2017.00150

18. Brooks AN, Beer KD. NIH Public Access. 2012; 1-24. doi:10.1002/wsbm.136.Adaptation

19. Cletus P. Kurtzman, Jack W. Fell TB. The Yeasts, a Taxonomic Study. Elsevier; 2011.

20. Garriga M, Almaraz M, Marchiaro A. Actas de Ingeniería Determination of reducing sugars in extracts of Undaria pinnatifida ( harvey ) algae by UV-visible spectrophotometry ( DNS method ) Determinación de azúcares reductores en extractos de alga Undaria pinnatifida ( harvey ) por espectrofo. 2017; 173-179.

21. Hadwan MH. New Method for Assessment of Serum Catalase Activity. 2016;9. doi:10.17485/ijst/2016/v9i4/80499

22. Ramos A, Tomotani EJ, Vitolo M. Invertase, glucose oxidase and catalase for converting sucrose to fructose and gluconic acid through batch and membrane- continuous reactors. 2011;47.

23. Torres MA, Barros MP, Campos SCG, Pinto E, Rajamani S, Sayre RT, et al. Ecotoxicology and Environmental Safety Biochemical biomarkers in algae and marine pollution: A review. 2008;71: 1-15. doi:10.1016/j.ecoenv.2008.05.009

24. Pada Dolai D. Study the Chromium-Induced Oxidative Stress on Mitochondria from Liver and Lungs Origin. Am J Appl Sci Res. 2016;2: 59. doi:10.11648/j.ajasr.20160206.15

25. Walton PA, Pizzitelli M. Effects of peroxisomal catalase inhibition on mitochondrial function. 2012;d: 1-10. doi:10.3389/fphys.2012.00108

26. Suraniti E, Ben-Amor S, Landry P, Rigoulet M, Fontaine E, Bottari S, et al. Electrochemical monitoring of the early events of hydrogen peroxide production by mitochondria. Angew Chemie - Int Ed. 2014;53: 6655-6658. doi:10.1002/anie.201403096

27. Xiang L, Ende W Van Den. Trafficking of Plant Vacuolar Invertases : From a Membrane-Anchored to a Soluble Status . Understanding Sorting Information in Their Complex N-Terminal Motifs. 2013;54: 1263-1277. doi:10.1093/pcp/pct075

28. Giardina T. Sucrose and invertases, a part of the plant defense response to the biotic stresses RESPONSE. 2014;5: 1-8. doi:10.3389/fpls.2014.00293

29. Emregül E, Sungur S, Akbulut U. Polyacrylamide-gelatine carrier system used for invertase immobilization. Food Chem FOOD CHEM. 2006;97. doi:10.1016/j.foodchem.2005.05.017 